\title{
Comparing occasional and persistent frequent attenders in occupational health primary care - a longitudinal study
}

\author{
Tiia Reho ${ }^{1,2^{*}}$ (D), Salla Atkins ${ }^{1,3}$, Nina Talola', Markku Sumanen ${ }^{1}$, Mervi Viljamaa ${ }^{2}$ and Jukka Uitti ${ }^{1,4,5}$
}

\begin{abstract}
Background: The aim of the study was to compare occasional and persistent frequent attenders in occupational health $(\mathrm{OH})$ primary care and to identify the diagnoses associated with persisting frequent attendance.

Methods: This is a longitudinal study using electronic medical record data from 2014 to 2016 from an OH service provider. Frequent attenders were defined as patients in the top decile of annual visits to healthcare professionals (frequent attender 10\%, FA10). FA10 were categorized to three groups according to the persistence of frequent attendance (1-year-FA, 2 year-FA, and persistent-FA = frequent attenders in all three years). This was used as the dependent variable. We used patient sex, age, employer size, industry and distribution of visits and diagnostic codes to characterize the different frequent attender groups.
\end{abstract}

Results: In total, 66,831 patients were included, of which 592 persistent frequent attenders ( $0.9 \%$ of the study population) consulted the $\mathrm{OH}$ unit on average 13 times a year. They made altogether 23,797 visits during the study years. The proportion of women and employees of medium and large employers increased among persistent-FAs when compared to the other groups. Multinomial logistic regression accentuated musculoskeletal disorders and to a lesser extent diseases of the respiratory and nervous system and mental disorders. One in five FA becomes a persistent-FA.

Conclusions: Our results indicate that in the context of a working population the association of musculoskeletal disorders and persistent frequent attendance is emphasized. Persistent frequent attenders also create a substantial demand on physician resources. When planning interventions aimed at working age frequent attenders, subgroups suffering from musculoskeletal disorders should be identified as they are associated with persisting frequent attendance.

Keywords: Frequent attender, High user, High utilizer, Occupational health services, Persistent frequent attendance, Primary health care, Health care utilization, Longitudinal studies

\section{Background}

Frequent attenders demand a substantial portion of physician's time and consume a considerable share of health care resources [1-3]. Some patients consult their physician repeatedly for a short period and return to an irregular pattern of attendance after some time [3, 4]. Another group of patients, often referred to as persistent frequent attenders, visit health care providers frequently one year after another $[3,5]$. Though studies on persistent frequent attendance are sparse, and concentrate on a

\footnotetext{
* Correspondence: tiia.reho@gmail.com

'Faculty of Medicine and Life Sciences, University of Tampere, PB 100, Fl-33014 Tampere, Finland

${ }^{2}$ Pihlajalinna Työterveys, Tampere, Finland

Full list of author information is available at the end of the article
}

general practice setting, it appears that a combination of somatic, psychological and psychiatric, and social factors lead to persistent frequent attendance [4-6]. In order to purposefully direct resources and to provide adequate treatment and rehabilitation, we need to be able to recognize individuals at risk of continuous high use of services with the routine data available during consultations. In addition, the differentiation of occasional and persistent frequent attenders could be useful for service planning as studies suggest that persistent FA's consume an even larger proportion of physicians time yearly than occasional FA's, and present more social problems and higher morbidity $[3,5]$ than occasional FA's.

(c) The Author(s). 2018 Open Access This article is distributed under the terms of the Creative Commons Attribution 4.0 International License (http://creativecommons.org/licenses/by/4.0/), which permits unrestricted use, distribution, and reproduction in any medium, provided you give appropriate credit to the original author(s) and the source, provide a link to the Creative Commons license, and indicate if changes were made. The Creative Commons Public Domain Dedication waiver (http://creativecommons.org/publicdomain/zero/1.0/) applies to the data made available in this article, unless otherwise stated. 
Previous research suggests that frequent attenders suffer from multimorbidity [6, 7] and low quality of life [8]. Studies also indicate that unemployment is associated with frequent attendance especially among men $[9,10]$ but few studies thus far have concentrated on frequent attendance among the working population [11]. Studies conducted in general practice or secondary care setting do not address the demands of the working life. Given that work has beneficial effects on health [12] but also places demands on work ability, the working population should be examined also separately. Studying the working population could yield different results possibly emphasizing illnesses that restrict work ability. Finnish occupational health $(\mathrm{OH})$ primary care is an appropriate environment to study frequent attenders in working population, as it covers $90 \%$ of the employees [13] and maintains comprehensive health records.

Visits to occupational health services (OHS) primary care are associated with chronic illnesses affecting work ability and work related symptoms [14]. Chronic health issues are also associated with lower productivity at work [15] and lowered work ability, which supports their being treated and managed in OHS. The most common work-related visits to the $\mathrm{OH}$ physician are musculoskeletal and mental disorders [16], which are both also leading causes of disability in Finland [17] and linked to frequent attendance in general practice setting and $\mathrm{OH}$ primary care $[11,18,19]$. This suggests that frequent attenders in $\mathrm{OH}$ primary care might be a vulnerable group of patients demanding careful assessment of work ability, work relatedness and follow up. Given the complexity of frequent attenders' conditions and the resource demand they create, it is crucial that their conditions are identified as early as possible. It is also pertinent to differentiate characteristics and factors associated with occasional and persistent frequent attendance to determine which groups need $\mathrm{OH}$ interventions. Identifying the risk groups would allow targeted $\mathrm{OH}$ examinations, where health plans and necessary rehabilitative measures and work place interventions can be planned to prevent disability [20].

We aimed to compare occasional and persistent frequent attenders and to define factors associated with persistent frequent attendance in $\mathrm{OH}$ primary care.

\section{Material and methods}

\section{Study setting and design}

Primary health care services in Finland are organized in three parallel structures: municipal, private and occupational health care $(\mathrm{OH})$. Preventive occupational health services are mandated by law and employers arrange these services for employees. In addition most employers arrange for the same health care provider that provides legislative services also to provide primary care services for employees -
$\mathrm{OH}$ primary care covers approximately $90 \%$ of the working force [13].

This is a longitudinal retrospective study using routine medical record data from a large private OHS provider Pihlajalinna Työterveys which has $40 \mathrm{OH}$ units around the nation. A longitudinal study design was chosen to analyze predictive factors associated with persisting frequent attendance. Pihlajalinna Työterveys' clients represent the working population of Finland including companies from a wide range of industries and rural as well as urban areas. In OHS primary care patients can use services of different health care professionals who are usually specialized in occupational health: physicians, nurses, physiotherapist and psychologists. A referral from a nurse or physician is required for a physiotherapist or psychologist consultation and physicians can consult other medical specialists. In Finland occupational health negotiations (referred to as $\mathrm{OH}$ collaborative negotiation) [21] are held confidentially between the occupational health physician, employee and employer whenever concerns are raised on the individuals work ability.

\section{Data collection}

Our data consisted of routine information, including diagnostic codes, entered during all visits to healthcare professionals in 2014-2016. The data also included background data, such as age and sex of the employee and employer's size and industry. Information on $\mathrm{OH}$ collaborative negotiations held was also obtained. The data were collected by Pihlajalinna and sent in pseudonymized form to the University of Tampere. Pseudonymization was carried out by Pihlajalinna Työterveys and University of Tampere received the data including only ID-number than cannot be associated with a single patient. The corresponding social security number and ID-list was kept by Pihlajalinna. Based on Finnish legislation (Personal Data Act, Finland, 22.4.1999) individual consent is unnecessary since no individual could be identified due to the size of the study population.

Our initial data comprised 78,507 patients. The study material was limited to employees aged 18-68 years who had visited the OHS primary care face-to-face at least once during the study years. All general and mandatory health check-ups and contacts not conducted face-to-face (prescription renewals, telephone calls etc.) were excluded based on invoice codes. General and mandatory (occupational) health check-ups were excluded as they are not initiated by the patient nor are they necessarily illness related. After these exclusions our study comprised 66,831 patients. Diagnostic codes (ICD-10) registered for each physician visit were collected and the first (i.e. the main) diagnosis was used in the analysis. 


\section{Statistical analysis}

Frequent attendance was defined as top decile of attenders $[3,22]$. Visits to physicians, nurses, physiotherapist and psychologists were used to determine the top decile of attenders (frequent attender 10\%, FA). Patients were then categorized into four groups for analysis. Those patients that were in the top decile of attenders in one of the study years $(2014,2015$ or 2016) were named 1-year-FA (1yFA). The patients that were in the top decile in any two study years were named 2-year-FA (2yFA). Those patients that were in the top decile in all three study years were considered persistent frequent attenders (pFA). Patients that were never in the top decile were considered as a reference group, non-frequent attenders (non-FA). A flow diagram of patient categorization and loss to follow up is shown in diagram 1 (Fig.1).

The study population was divided into four age groups $(18-34,35-44,45-54,55-68)$ and further by sex. In further analysis no age stratification was done since the whole study population consists of working age population. Employers were categorized according to number of employees (micro 1-10, small 11-50, medium 51-250 and large > 251 employees). The employer industry was classified according to Statistics Finland (TOL2008/Nace Rev. 2) and the 10 largest industries were analyzed separately and the 10 smaller industries were combined as one group (others). Diagnoses registered at the physician visits were categorized according to the chapter headings of ICD-10. ICD-10 subgroups were defined in more detail based on previous literature $[3,18,19]$ and to examine the largest diagnostic groups more closely [11].

Descriptive statistics were used to examine demographic data, $\mathrm{OH}$ collaborative negotiation and background data including employer size and industry of the frequent attenders groups (1yFA, 2yFA, pFA or non-FA). Differences between the groups in characteristics were analyzed using Pearson's chi-square. One-way ANOVA tests was used to analyze the number of visits to different health care professionals as a whole and the distribution of visits between different professional groups. Kruskal-Wallis -test was used to analyze differences between the groups in the number of diagnoses. In multinomial logistic regression the outcome variable was categorized into four: non-FA, $1 \mathrm{yFA}, 2 \mathrm{yFA}$ and pFA. We used the non-FA group as a reference group. The analysis was adjusted by sex, age, employer's field of industry and size. Odds ratios (OR) with 95\%

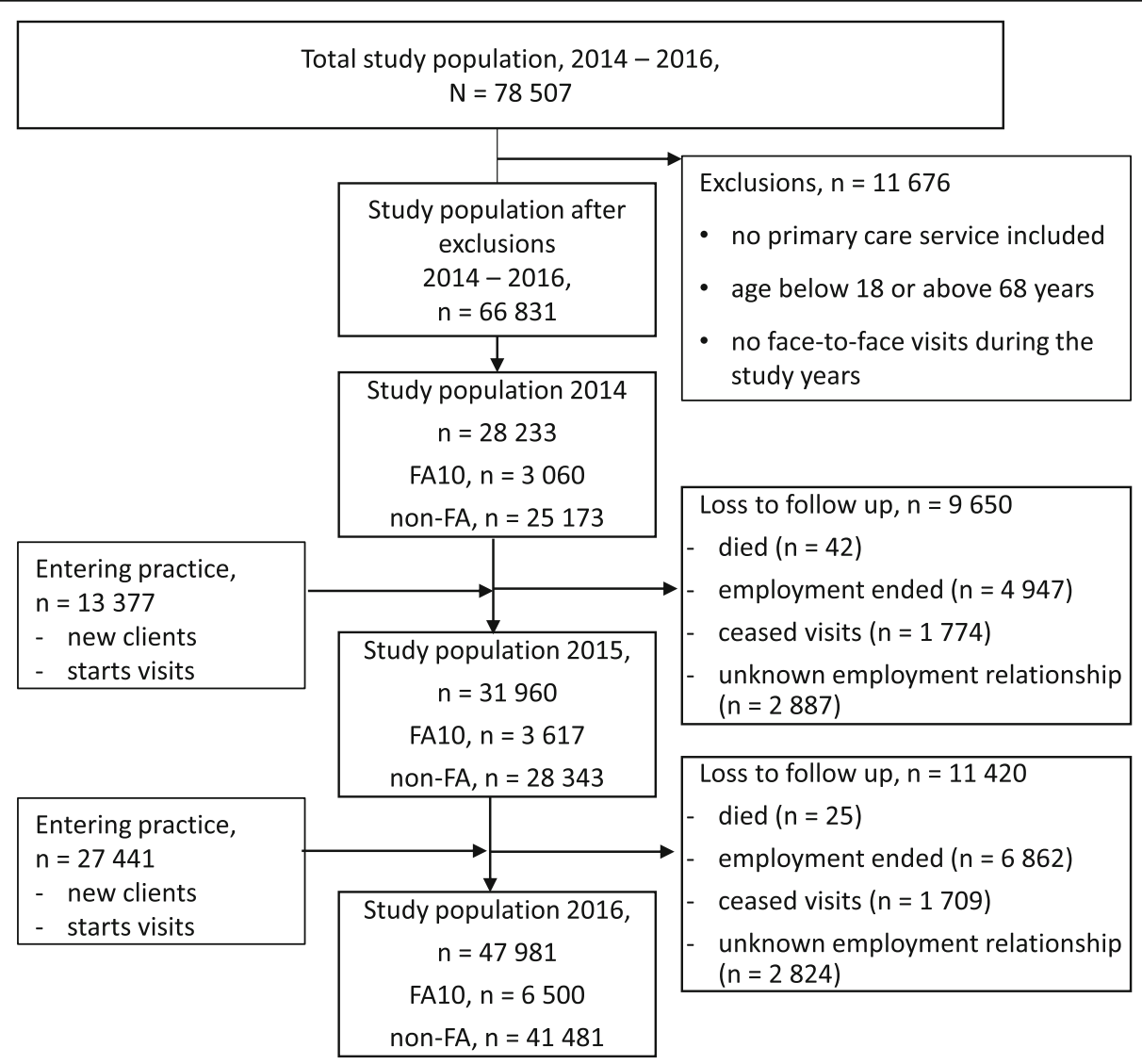

Fig. 1 Flow diagram of patient categorization into FA10 and non-FA. FA10 = the top decile of attenders (frequent attender 10\%, FA10). non-FA= patients that were never in the top decile were considered as a reference group, non-frequent attenders 
confidence intervals $(95 \% \mathrm{CI})$ were determined for each factor (professionals visited, diagnosis). $P$ values under 0.05 were considered statistically significant. Statistical analyses were performed with IBM SPSS Statistics version 23 (IBM Corp., Armonk, NY, USA) software by NT.

\section{Results}

The study population after exclusions comprised 66,831 patients (2014-2016). When divided into four categories $592(0.9 \%)$ patients were pFAs, 1603 (2.4\%) 2yFAs, 6528 (9.8\%) 1yFAs and 58,108 (86.9\%) non-FAs. Proportionally more women ( $50 \%$ of $1 \mathrm{yFA}, 53 \%$ of $2 \mathrm{yFA}$ and $56 \%$ of pFA) than men were frequent attenders (and the proportion of women increased in 2yFAs and pFAs). Frequent attenders were predominantly employed in medium and large companies (Table 1). The three largest industries employing frequent attenders were manufacturing, public administration and human health and social work (data not shown). The use of other professionals besides physicians increased as frequent attendance continued. 2yFAs and pFAs consult with a psychologists, physiotherapists and specialists more often than non-FAs and 1yFAs do. In addition, the likelihood of occupational health negotiation increased as frequent attendance persisted. See Table 1 for further characteristics.

The average and mean consultation rates can be seen in Table 2. Persistent frequent attenders consult with a healthcare professional yearly over five times more than non-FAs do. The differences between consultation rates were notable in physician consultations but the same trend was seen also with other health care professionals. Over the three study years, pFAs attended their $\mathrm{OH}$ primary care unit 40 times on average whereas a non-FA visited on average 4 times. Most of these consultations were doctor's appointments. Over the three year period physiotherapists were consulted on average 1.3, 2.6, 4.0 and 0.2 times (md 0, 1, 2 and 0 ) by 1yFA, 2yFA, pFA and non-FA respectively. Over the same period psychologists were consulted on average 1.4 times by pFA and $0.6,1.3$ and 0.08 times (md 0 ) by $1 \mathrm{yFA}, 2 \mathrm{yFA}$ and non-FA respectively.

Table 3 includes the distribution of diagnoses for $1 \mathrm{yFA}$, 2yFA, pFA and non-FA. When examining the diagnostic codes registered for each physician visit, the most common diagnostic codes for any group were diseases of the respiratory system and of the musculoskeletal system. Diseases of the musculoskeletal system were overrepresented in frequent attender groups and their frequency increased towards persistent frequent attendance. The same trend is visible in all the diagnostic groups and is accentuated also in mental and behavioural disorders, injuries and unclassified symptoms. During the three study years average number of different diagnoses was 4.2 (md 4), 5.8 (md 6), 6.9 (md 7) and 2.0 (md 2) for 1yFA, 2yFA, pFA and non-FA respectively ( $p<0.001$, Kruskal-Wallis -test).
Table 4 shows the adjusted OR for factors associated with frequent attendance of varying lengths. The same ICD-10 categories dominated in all three categories but the proportions differed to some extent. Among pFA diseases of the musculoskeletal and respiratory system had the highest odds, followed by unclassified symptoms (R00-R99). On the other hand among 1yFAs musculoskeletal and mental disorders were the leading diagnoses and diseases of the nervous system had the third highest OR. Among 2yFAs musculoskeletal and respiratory diseases dominated but mental and behavioural disorders were third most common. Diseases of the nervous system and injuries stood out in all three FA categories. When examining the ICD-10 F-codes more closely we noted that for depressive episodes the adjusted OR for pFA was 12.0 (95\% CI 9.5-15.2) and for phobic disorders 8.5 (95\% CI 6.511.0). For illnesses of the back and spine OR for pFA was 13.5 (95\% CI 11.3-16.1) and illnesses of the neck, cervical spine and tension headache the OR was 10.47 (95\% CI 8.9-12.4). For illnesses of the upper extremities the OR was 8.9 (95\% CI 7.5-10.5) and for illnesses of the lower extremities 7.9 (95\% CI 6.7-9.4). Again, for pFA the OR for asthma and COPD was 8.3 (95\% CI 6.4-10.7) while for acute upper respiratory infections the OR was 13.4 (95\% CI 10.7-16.9) (data not shown). We also saw that psychologist and physiotherapist use was associated with 2yFAs and pFAs (Table 4). The OR increases over years when frequent attendance continues especially with regard to physiotherapist, psychologist, and specialist consultations.

\section{Discussion}

Nearly one in five frequent attenders in 2014 continued frequent use of services for the following two years. Persistent FAs are frequently women and employed in medium and large enterprises. Musculoskeletal disorders are more closely associated with pFA than other diagnostic groups. The association with mental disorders weakens as frequent attendance continues. The reasons for this effect should be examined further.

This study verifies in Finnish OH primary care environment that persistent frequent attenders create proportionally the most demand for the health care unit as previously seen in general practice (GP) setting [3]. The use of services and in particular physician consultations is substantial compared to non-FAs and also $1 \mathrm{yFAs}$ and $2 \mathrm{yFAs}$. The pFA group of 592 patients made 23,797 visits to their primary care unit during the three study years. Given the cost of a physician visit compared to visits to other health care professionals, the economic effect created by this small group is notable. In our study nearly one out of five (19\%) of FAs in 2014 continued as persistent frequent attenders, which is slightly more than in a Dutch study in general practice setting [3]. While the group of pFAs constituted $0.9 \%$ of the study 
Table 1 Study population 2014-2016, characteristics of 1-year-FA, 2-year-FA, pFA and non-FA ( $n=66,831)$

\begin{tabular}{|c|c|c|c|c|c|c|c|c|c|}
\hline \multirow[t]{2}{*}{ Characteristics } & \multicolumn{2}{|c|}{$\begin{array}{l}\text { 1-year-FA } \\
2014-2016\end{array}$} & \multicolumn{2}{|c|}{$\begin{array}{l}\text { 2-year-FA } \\
2014-2016\end{array}$} & \multicolumn{2}{|c|}{$\begin{array}{l}\text { pFA } \\
2014-2016\end{array}$} & \multicolumn{2}{|c|}{$\begin{array}{l}\text { non-FA } \\
2014-2016\end{array}$} & \multirow[t]{2}{*}{$p$ value } \\
\hline & $n$ & $(\%)$ & $n$ & $(\%)$ & $n$ & $(\%)$ & $n$ & $(\%)$ & \\
\hline & 6528 & (10) & 1603 & (2) & 592 & (1) & 58,108 & (87) & \\
\hline Sex & & & & & & & & & $<0.001$ \\
\hline Male & 3270 & $(50)$ & 754 & $(47)$ & 262 & $(44)$ & 33,236 & (57) & \\
\hline Female & 3258 & $(50)$ & 849 & (53) & 330 & $(56)$ & 24,872 & (43) & \\
\hline Age & & & & & & & & & $<0.001$ \\
\hline $18-34$ & 1661 & $(25)$ & 354 & $(22)$ & 128 & $(21)$ & 19,630 & (34) & \\
\hline $35-44$ & 1641 & $(25)$ & 413 & $(26)$ & 147 & $(25)$ & 13,648 & (23) & \\
\hline $45-54$ & 1889 & (29) & 473 & (30) & 187 & $(32)$ & 14,351 & (25) & \\
\hline $55-68$ & 1337 & $(21)$ & 363 & $(22)$ & 130 & $(22)$ & 10,479 & (18) & \\
\hline Company size & & & & & & & & & $<0.001$ \\
\hline $0-10$ & 507 & (8) & 77 & (5) & 19 & (3) & 8544 & (15) & \\
\hline $11-50$ & 1601 & $(25)$ & 350 & $(22)$ & 129 & $(22)$ & 16,036 & (28) & \\
\hline $51-250$ & 1767 & $(27)$ & 513 & $(32)$ & 195 & $(32)$ & 14,165 & (24) & \\
\hline$>250$ & 2287 & (35) & 663 & $(41)$ & 249 & $(42)$ & 16,451 & (28) & \\
\hline Missing & 2 & (0) & & & & & 16 & (0) & \\
\hline Specialist consultation & & & & & & & & & $<0.001$ \\
\hline No & 4677 & $(72)$ & 894 & $(56)$ & 244 & $(41)$ & 51,622 & (89) & \\
\hline Yes & 1851 & (28) & 709 & $(44)$ & 348 & (59) & 6486 & (11) & \\
\hline Professionals visited & & & & & & & & & $<0.001$ \\
\hline Physician & 6513 & $(100)$ & 1603 & $(100)$ & 592 & $(100)$ & 53,945 & (93) & \\
\hline Nurse & 4119 & (63) & 1192 & (74) & 460 & (78) & 18,918 & (33) & \\
\hline Physiotherapist & 2932 & $(45)$ & 1023 & $(64)$ & 425 & $(72)$ & 7910 & (14) & \\
\hline Psychologist & 1174 & (18) & 467 & (29) & 196 & (33) & 1966 & (3) & \\
\hline \multicolumn{5}{|c|}{ OH collaborative negotiation (2014-2015) } & & & & & $<0.001$ \\
\hline No & 6309 & $(97)$ & 1424 & (89) & 453 & (77) & 57,490 & (99) & \\
\hline Yes & 219 & (3) & 179 & (11) & 139 & $(23)$ & 618 & (1) & \\
\hline
\end{tabular}

FA status was defined as the top decile of attenders (frequent attender 10\%, FA10)

1 -year-FA = Patients that were in the top decile of attenders in one of the study years (2014, 2015 or 2016)

2 -year-FA = Patients that were in the top decile in any two study years $(2014,2015$ or 2016)

pFA = Patients that were in the top decile in all three study years (2014, 2015 and 2016)

non-FA = Patients that were never in the top decile were considered as a reference group, non-frequent attenders

population, they made $6 \%$ of all visits in the three study years. The three frequent attender groups $(\mathrm{pFA}, 2 \mathrm{yFA}$ and 1yFA) made up in total $40 \%$ of all consultations.

Our study is the first to describe how the use of other healthcare professionals varies between occasional and persistent frequent attenders. Visits to physiotherapists and psychologists were associated with persisting frequent attendance in particular and having consulted either them or a specialist increases the OR of belonging to pFA to almost 15. In this study we described how frequent attenders consult other healthcare professionals. It appears that although the use of physiotherapists and psychologists increases with pFAs, the dominance of physicians' appointments is marked. Previously, in a GP setting specialist consultations have been linked to frequent attendance and use of multiple healthcare services to multimorbidity $[7,23]$. Our study verifies the association of specialist consultation and frequent attendance and specifies the association with particularly persisting frequent attendance.

The significance of musculoskeletal disorders accumulates towards persisting frequent attendance. If diagnosed with a musculoskeletal disorder, the OR for being a pFA are over 26-fold (when adjusted for age, sex, employee size and industry). Although the association of musculoskeletal disorders and frequent attendance has been noted previously $[18,24,25]$ its significance seems emphasized in the working population. Previous studies noted that musculoskeletal disorders are associated with visits to $\mathrm{OH}$ physicians and are one of the main work-related reasons for healthcare consultations [26, 27], which might explain this result in 
Table 2 Association between consultation visits and frequent attender status ( $n=28,233-66,831)$

\begin{tabular}{|c|c|c|c|c|c|c|}
\hline \multirow[t]{2}{*}{ Characteristics } & \multicolumn{2}{|c|}{ Consultations, all } & \multicolumn{2}{|c|}{ Physician } & \multicolumn{2}{|c|}{ Nurse } \\
\hline & av. & md & $\mathrm{av}$. & $\mathrm{md}$ & av. & $\mathrm{md}$ \\
\hline $\begin{array}{l}2014 \\
(n=28,233)\end{array}$ & $* * *$ & & $* * *$ & & $* * *$ & \\
\hline 1-year-FA & 4.9 & 4 & 3.6 & 3 & 0.7 & 0 \\
\hline 2-year-FA & 7.7 & 8 & 5.6 & 5 & 1.1 & 0 \\
\hline $\mathrm{pFA}$ & 13.2 & 11 & 9.6 & 9 & 1.8 & 1 \\
\hline non-FA & 2.9 & 2 & 2.3 & 2 & 0.4 & 0 \\
\hline $\begin{array}{l}2015 \\
(n=31,960)\end{array}$ & $* * *$ & & $* * *$ & & $* * *$ & \\
\hline 1-year-FA & 5.7 & 5 & 4.1 & 4 & 0.8 & 0 \\
\hline 2-year-FA & 10.2 & 9 & 7.3 & 7 & 1.4 & 1 \\
\hline $\mathrm{pFA}$ & 14.3 & 13 & 10.6 & 10 & 1.8 & 1 \\
\hline non-FA & 2.7 & 2 & 2.1 & 2 & 0.4 & 0 \\
\hline $\begin{array}{l}2016 \\
(n=47,981)\end{array}$ & $* * *$ & & $* * *$ & & $* * *$ & \\
\hline 1-year-FA & 7.8 & 8 & 5.5 & 5 & 1.2 & 0 \\
\hline 2-year-FA & 9.4 & 9 & 6.7 & 6 & 1.2 & 0 \\
\hline $\mathrm{pFA}$ & 12.6 & 11 & 9.4 & 8 & 1.5 & 1 \\
\hline non-FA & 2.4 & 2 & 1.9 & 1 & 0.4 & 0 \\
\hline $\begin{array}{l}2014-2016 \\
(n=66,831)\end{array}$ & $* * *$ & & $* * *$ & & $* * *$ & \\
\hline 1-year-FA & 13.8 & 13 & 9.9 & 9 & 2.1 & 1 \\
\hline 2-year-FA & 26.4 & 25 & 19.0 & 19 & 3.6 & 2 \\
\hline $\mathrm{pFA}$ & 40.0 & 37 & 30.0 & 28 & 5.1 & 3 \\
\hline non-FA & 4.0 & 3 & 3.1 & 2 & 0.6 & 0 \\
\hline
\end{tabular}

One-way ANOVA -test, av. = average, $\mathrm{md}=$ median, $p<0.001$ in all values FA status was defined as the top decile of attenders (frequent attender $10 \%, \mathrm{FA} 10)$

1 -year-FA = Patients that were in the top decile of attenders in one of the study years $(2014,2015$ or 2016)

2 -year-FA $=$ Patients that were in the top decile in any two study years (2014, 2015 or 2016)

pFA = Patients that were in the top decile in all three study years $(2014,2015$ and 2016)

non-FA = Patients that were never in the top decile were considered as a reference group, non-frequent attenders

$\mathrm{OH}$ primary care. This result suggests that among the working age population diseases of the musculoskeletal system can be a more important factor driving frequent attendance than in the general practice setting. This is an observation that should be taken into account when planning identification and intervention strategies for frequent attenders in this context.

Our findings suggest that in particular those frequent attenders diagnosed with musculoskeletal disorders should be identified early. A follow up plan should be prepared, where a multiprofessional approach could be used in the spirit of Good Occupational Health Practice and the Occupational Health Care Act [28]. The accumulating pressure and weight on the system from frequent attendance is significant and cost-savings might be obtained if utilization could be increasingly planned and managed. Deeper analysis behind reasons for attendance [29] could be acquired through collaboration with other health care professionals.

OHS has close contact with the employers allowing, with the consent of the employee, also workplace interventions if seen necessary [30]. Although the likelihood of $\mathrm{OH}$ collaborative negotiation increases as the frequent use of services continues, these negotiations have been held for only $23 \%$ of pFA. Further studies should investigate if having attended an $\mathrm{OH}$ collaborative negotiation affects future frequent attendance. Interventions aimed at frequent attendance have shown encouraging results when subgroups such as depressed patients are targeted or a detailed analysis of reasons for attendance are carried out [29, 31]. If work related symptoms and performance difficulties cause visits to $\mathrm{OH}$ unit, workplace interventions, including $\mathrm{OH}$ collaborative negotiations, might be an effective way to address medically unsolvable reasons for attendance.

The association with mental and behavioural disorders also grows as frequent attendance persists, but diseases of the respiratory and nervous system show higher odds in association with pFA. An Estonian study found that depressed patients did not consult a physician significantly more than others when the follow up period was three years [32]. Effective recovery could explain this also in our study. However as mental disorders are one of the most common reasons for disability pensions, this issue should be studied further. It is not known if frequent attenders receive more disability pensions for mental disorders than others, which could also cause mental health diagnoses being less significant in the pFA group. Also in Finland, mental and behavioural disorders can also be treated in mental health services and units of secondary care. If a mental disorder persists, patients are often referred to these units. This might be one factor explaining why mental disorders appear less significant with pFA group. Similarly to Australian and Dutch primary care studies we found that persistent frequent attendance was associated with depression, but on the other hand we did not find an association with diabetes or heart problems $[3,5]$. This might be due to our study material comprising of solely a working age population, some of whom may consult public practitioners for chronic diseases $[26,33]$. The $\mathrm{OH}$ primary care setting most likely emphasizes the problems and illnesses affecting working ability [14].

The findings also indicate that respiratory diseases and diseases of the nervous system are closely associated with persistent high use of services in the working age population. An association of persistent high use of services with respiratory diseases has previously been reported in a primary care setting [3] and diseases of the nervous system have been associated with frequent attendance, but this confirms the connection also in persistent frequent attendance 
Table 3 Patients diagnosed with a disease according to ICD-10 (registered for physician consultations in the study years 2014-2016, $n=66,831)$

\begin{tabular}{|c|c|c|c|c|c|c|c|c|}
\hline \multirow[t]{2}{*}{ Characteristics } & \multicolumn{2}{|c|}{$\begin{array}{l}\text { 1-year-FA } \\
2014-2016\end{array}$} & \multicolumn{2}{|c|}{$\begin{array}{l}\text { 2-year-FA } \\
2014-2016\end{array}$} & \multicolumn{2}{|c|}{$\begin{array}{l}\text { pFA } \\
2014-2016\end{array}$} & \multicolumn{2}{|c|}{$\begin{array}{l}\text { non-FA } \\
2014-2016\end{array}$} \\
\hline & $n$ & (\%) & $n$ & (\%) & $n$ & $(\%)$ & $n$ & $(\%)$ \\
\hline & 6528 & $(10)$ & 1603 & $(2)$ & 592 & (1) & 58,108 & $(87)$ \\
\hline \multicolumn{9}{|l|}{ ICD-10 } \\
\hline J00-J99 Diseases of the respiratory system & 4254 & $(65.2)$ & 1321 & $(82.4)$ & 536 & $(90.5)$ & 23,678 & $(40.7$ \\
\hline M00-M99 Diseases of the musculoskeletal system and connective tissue & 4796 & $(73.5)$ & 1422 & $(88.7)$ & 559 & $(94.4)$ & 21,303 & $(36.7$ \\
\hline $\begin{array}{l}\text { R00-R99 Symptoms, signs and abnormal clinical and laboratory } \\
\text { findings, not elsewhere classified }\end{array}$ & 2309 & $(35.4)$ & 857 & $(53.5)$ & 401 & $(67.7)$ & 9147 & $(15.7$ \\
\hline S00-T98 Injury, poisoning and certain other consequences of external causes & 2198 & $(33.7)$ & 792 & $(49.4)$ & 349 & $(59.0)$ & 9228 & $(15.9$ \\
\hline L00-L99 Diseases of the skin and subcutaneous tissue & 1335 & $(20.5)$ & 510 & $(31.8)$ & 220 & $(37.2)$ & 5717 & $(9.8)$ \\
\hline F00-F99 Mental and behavioural disorders & 1595 & $(24.4)$ & 609 & $(38.0)$ & 270 & $(45.6)$ & 4663 & $(8.0)$ \\
\hline 100-199 Diseases of the circulatory system & 1129 & $(17.3)$ & 403 & $(25.1)$ & 168 & $(28.4)$ & 4902 & $(8.4)$ \\
\hline A00-B99 Certain infectious and parasitic diseases & 1102 & $(16.9)$ & 425 & $(26.5)$ & 228 & $(38.5)$ & 4827 & $(8.3)$ \\
\hline H00-H59 Diseases of the eye and adnexa & 868 & (13.3) & 326 & $(20.3)$ & 163 & $(27.5)$ & 4056 & $(7.0)$ \\
\hline H60-H95 Diseases of the ear and mastoid process & 909 & $(13.9)$ & 315 & $(19.7)$ & 153 & $(25.8)$ & 3687 & $(6.3)$ \\
\hline
\end{tabular}

ICD-10 = International Classification of Diseases

FA status was defined as the top decile of attenders (frequent attender 10\%, FA10), $p<0.001$ in all values

1 -year-FA $=$ Patients that were in the top decile of attenders in one of the study years (2014, 2015 or 2016)

2-year-FA = Patients that were in the top decile in any two study years (2014, 2015 or 2016)

pFA = Patients that were in the top decile in all three study years $(2014,2015$ and 2016)

non-FA = Patients that were never in the top decile were considered as a reference group, non-frequent attenders

In the table are presented the 10 largest ICD-10 groups

[25]. In turn, the high OR for the ICD R-group can be seen as indicative of medically unexplained physical symptoms (MUPS). The association of MUPS with persistent frequent attendance has been seen also in general practice setting [3] and is of importance as also medically unexplained symptoms increase the risk of long-term sickness absence [34]. The finding that injuries have higher odds for persistent FA is interesting, and might reinforce the perception that persistent frequent attenders are more vulnerable as also indicated in a previous study [35]. Multimorbidity is associated with frequent attendance and appears to increase as frequent attendance persists, as also seen previously [3]. As a whole, no single factor differentiates these groups from each other but rather, these factors seem to exist on a continuum.

Our study has certain limitations. Our study population differs from the general practice setting to some extent in terms of patient age and working status, and we assume that these demographic differences possibly accentuate different factors than what would rise in general practice setting. The lack of occupational status and education are limitations to the study as these are not available in medical records. Human error may be present when using medical record data, but the large sample likely dilutes the effect. Retrospective study sets limitations to variables used, which are also limited by what is and can be registered in the electronic patient registers.
On the other hand our data allow a unique perspective to this particular group given our nationwide material covering largely different service sectors and both rural and urban areas with employees with variety of employment lengths and industries. The distribution of employers' size and industry resembles the general distribution of employers according to Statistics Finland [36]. The equal age distribution within the working age population and equal gender distribution, allows generalization outside this particular context. Strengths of the study are large sample and longitudinal study design allowing for interpretation of predictive factors of persistent frequent attendance. The health care records in Finland are accurate and comprehensive allowing for good quality data. For example, the ICD-10 classified diagnostic code was missing in only $1 \%$ of the visits. In this study we did not have access to use of other health care services, but a previous study indicates that when OHS primary care is available it is often used as sole primary care provider [26].

\section{Conclusions}

Diseases of the musculoskeletal system are emphasized among persistent frequent attenders of occupational health primary care. This could be explained by the demands of working life or that the conditions are work-related. As it seems that persistent frequent attenders create the most demand for their primary care unit, it is necessary 
Table 4 Factors associated with frequent attendance in multinomial logistic regression $(n=66,831)$

\begin{tabular}{|c|c|c|c|c|c|c|c|c|c|}
\hline \multirow[b]{2}{*}{ Factor } & \multicolumn{3}{|c|}{ 1-year-FA (2014-2016) } & \multicolumn{3}{|c|}{ 2-year-FA (2014-2016) } & \multicolumn{3}{|c|}{ pFA (2014-2016) } \\
\hline & $n$ & OR & $95 \% \mathrm{Cl}$ & $n$ & OR & $95 \% \mathrm{Cl}$ & $n$ & OR & $95 \% \mathrm{Cl}$ \\
\hline \multicolumn{10}{|l|}{ Professionals visited } \\
\hline Physician & 6513 & & & 1603 & & & 592 & & \\
\hline Nurse & 4119 & 3.43 & $3.25-3.63$ & 1192 & 5.39 & $4.80-6.06$ & 460 & 6.19 & $5.07-7.56$ \\
\hline Physiotherapist & 2932 & 4.73 & $4.48-5.00$ & 1023 & 9.59 & $8.62-10.7$ & 425 & 13.15 & $10.95-15.79$ \\
\hline Psychologist & 1174 & 6.19 & $5.71-6.70$ & 467 & 11.92 & $10.6-13.5$ & 196 & 14.44 & $11.99-17.40$ \\
\hline Specialist consultation & 1851 & 3.40 & $3.20-3.62$ & 709 & 7.61 & $6.84-8.47$ & 348 & 14.64 & $12.31-17.40$ \\
\hline \multicolumn{10}{|l|}{ ICD-10 } \\
\hline $\begin{array}{l}\text { M00-M99 Diseases of the musculoskeletal system and } \\
\text { connective tissue }\end{array}$ & 4796 & 4.59 & $4.33-4.86$ & 1422 & 12.58 & $10.8-14.7$ & 559 & 26.85 & $18.9-38.2$ \\
\hline J00-J99 Diseases of the respiratory system & 4254 & 2.88 & $2.73-3.05$ & 1321 & 7.50 & $6.57-8.55$ & 536 & 15.55 & $11.79-20.52$ \\
\hline $\begin{array}{l}\text { R00-R99 Symptoms, signs and abnormal clinical and } \\
\text { laboratory findings, not elsewhere classified }\end{array}$ & 2309 & 2.91 & $2.75-3.08$ & 857 & 6.13 & $5.55-6.79$ & 401 & 11.15 & $9.36-13.29$ \\
\hline $\begin{array}{l}\text { S00-T98 Injury, poisoning and certain other consequences } \\
\text { of external causes }\end{array}$ & 2198 & 2.87 & $2.71-3.03$ & 792 & 5.68 & $5.13-6.30$ & 349 & 8.58 & $7.25-10.15$ \\
\hline F00-F99 Mental and behavioural disorders & 1595 & 3.67 & $3.44-3.92$ & 609 & 7.05 & $6.33-7.85$ & 270 & 9.68 & $8.19-11.44$ \\
\hline L00-L99 Diseases of the skin and subcutaneous tissue & 1335 & 2.32 & $2.17-2.48$ & 510 & 4.15 & $3.72-4.63$ & 220 & 5.21 & $4.39-6.18$ \\
\hline A00-B99 Certain infectious and parasitic diseases & 1102 & 2.37 & $2.21-2.55$ & 425 & 4.34 & $3.86-4.88$ & 228 & 7.70 & $6.49-9.13$ \\
\hline 100-199 Diseases of the circulatory system & 1129 & 2.13 & $1.98-2.29$ & 403 & 3.38 & $2.99-3.81$ & 168 & 4.00 & $3.32-4.83$ \\
\hline G00-G99 Diseases of the nervous system & 976 & 3.03 & $2.80-3.27$ & 403 & 5.69 & $5.05-6.42$ & 220 & 10.00 & $8.41-11.89$ \\
\hline K00-K93 Diseases of the digestive system & 934 & 2.60 & $2.40-2.81$ & 379 & 4.75 & $4.20-5.36$ & 202 & 7.93 & $6.65-9.44$ \\
\hline
\end{tabular}

ICD-10 = International Classification of Diseases

$\mathrm{OR}=$ Odds ratio (adjusted by sex, age, company size and field of industry), $\mathrm{Cl}=$ Confidence interval

$1.0=$ reference group (non-FA = non-frequent attenders, patients that were never in the top decile were considered as a reference group)

FA status was defined as the top decile of attenders (frequent attender 10\%, FA10),

1 -year-FA $=$ Patients that were in the top decile of attenders in one of the study years $(2014,2015$ or 2016)

2 -year-FA = Patients that were in the top decile in any two study years $(2014,2015$ or 2016)

pFA = Patients that were in the top decile in all three study years (2014, 2015 and 2016)

In the table are presented the 10 largest ICD-10 groups

to further examine whether they are also at risk of disability and sickness absences. When planning future interventions aimed at frequent attenders, the subgroup suffering from musculoskeletal disorders should be considered. Among the working age patients, identified disorders' work-relatedness should be considered.

\section{Abbreviations}

Cl: Confidence interval; FA10: Frequent attender 10\% (patients in the top decile of annual visits to healthcare professionals); GP: General practice; MUPS: Medically unexplained physical symptoms; $\mathrm{OH}$ : Occupational health; OHS: Occupational health services; OR: Odds ratios

\section{Acknowledgements}

The authors acknowledge the participation of the occupational health staff in the study and all the individual clients who are part of this study.

\section{Funding}

This study is part of the "Effectiveness and Indicators of Occupational Health Services" supported by the European Social Fund [reference number S20659]. The funder had no role in the design of the study nor collection, analysis, and interpretation of data or in writing the manuscript.

\section{Availability of data and materials}

The data that support the findings of this study are available from Pihlajalinna Työterveys but restrictions apply to the availability of these data, which were used under license for the current study, and so are not publicly available. Data are however available from the authors upon reasonable request and with permission of Pihlajalinna Työterveys.

\section{Authors' contributions}

The study was conceptualized by $\mathrm{J}$ and the study design was planned by all the authors. Planning of data collection and analysis was done by all authors. NT analyzed the data. TR wrote the first draft and all authors contributed to the final version by revising and commenting on the draft. All authors approved the final version.

\section{Ethics approval and consent to participate}

The ethics committee of Pirkanmaa Hospital District (ETL R16041) and the National Institute of Health and Welfare (THL/556/5.05.00/2016) approved the study. Based on Finnish legislation (Personal Data Act, Finland, 22.4.1999) individual consent is unnecessary since no individual could be identified due to the size of the study population.

Consent for publication

Not applicable.

\section{Competing interests}

The authors' declare that they have no competing interests.

\section{Publisher's Note}

Springer Nature remains neutral with regard to jurisdictional claims in published maps and institutional affiliations. 


\section{Author details}

${ }^{1}$ Faculty of Medicine and Life Sciences, University of Tampere, PB 100 FI-33014 Tampere, Finland. ${ }^{2}$ Pihlajalinna Työterveys, Tampere, Finland. ${ }^{3}$ Department of Public Health Sciences, Karolinska Institutet, Stockholm, Sweden. ${ }^{4}$ Finnish Institute of Occupational Health, Tampere, Finland. ${ }^{5} \mathrm{Clinic}$ of Occupational Medicine, Tampere University Hospital, Tampere, Finland.

\section{Received: 23 February 2018 Accepted: 14 November 2018}

\section{Published online: 26 November 2018}

\section{References}

1. Neal RD, Heywood PL, Morley S, Clayden AD, Dowell AC. Frequency of patients' consulting in general practice and workload generated by frequent attenders: comparisons between practices. Br J Gen Pract. 1998;48:895-8.

2. Smits FT, Brouwer HJ, Zwinderman AH, Mohrs J, Smeets HM, Bosmans JE, et al. Morbidity and doctor characteristics only partly explain the substantial healthcare expenditures of frequent attenders: a record linkage study between patient data and reimbursements data. BMC Fam Pract. 2013;14. https://doi.org/10.1186/1471-2296-14-138.

3. Smits FT, Brouwer HJ, ter Riet G, van Weert HC. Epidemiology of frequent attenders: a 3-year historic cohort study comparing attendance, morbidity and prescriptions of one-year and persistent frequent attenders. BMC Public Health. 2009;9. https://doi.org/10.1186/1471-2458-9-36.

4. Carney TA, Guy S, Jeffrey G. Frequent attenders in general practice: a retrospective 20-year follow-up study. Br J Gen Pract. 2001;51:567-9.

5. Pymont C, Butterworth P. Longitudinal cohort study describing persistent frequent attenders in Australian primary healthcare. BMJ Open. 2015;5: e008975. https://doi.org/10.1136/bmjopen-2015-008975.

6. Gill D, Sharpe M. Frequent consulters in general practice. A systematic review of studies of prevalence, associations and outcome J Psychosom Res. 1999;47:115-30.

7. Droomers M, Westert GP. Do lower socioeconomic groups use more health services, because they suffer from more illnesses? Eur J Pub Health. 2004;14:311-3.

8. Kersnik J, Scvab I, Vegnuti M. Frequent attenders in general practice: quality of life, patient satisfaction, use of medical services and GP characteristics. Scand J Prim Health Care. 2001;19:174-7.

9. Scaife B, Gill P, Heywood P, Neal R. Socio-economic characteristics of adult frequent attenders in general practice: secondary analysis of data. Fam Pract. 2000;17:298-304.

10. Vedsted P, Olesen F. Social environment and frequent attendance in Danish general practice. Br J Gen Pract. 2005;55:510-5.

11. Reho T, Atkins S, Talola N, Sumanen M, Viljamaa M, Uitti J. Frequent attenders in occupational health primary care - a cross-sectional study. Scand J Public Health. 2018. https://doi.org/10.1177/1403494818777436.

12. Ross CE, Mirowsky J. Does employment affect health? J Health Soc Behav. 1995:36:230-43.

13. Lappalainen $K$, Aminoff $M$, Hakulinen $H$, Hirvonen M, Räsänen $K$, Sauni R, et al. Työterveyshuolto Suomessa vuonna 2015 [occupational healthcare in Finland 2015 report] (in Finnish with english summary). Työterveyslaitos; 2016. p. 19.

14. Kimanen A, Rautio M, Manninen P, Räsänen K, Husman P, Husman K. Primary care visits to occupational health physicians and nurses in Finland. Scand J Public Health. 2011;39:525-32.

15. Leijten FR, Van Den Heuvel SG, Ybema JF, Van Der Beek AJ, Robroek SJ, Burdorf A. The influence of chronic health problems on work ability and productivity at work: a longitudinal study among older employees. Scand J Work Env Heal. 2014;40:473-82.

16. Ikonen A. Primary care visits in the Finnish occupational health services and their connections to prevention and work-related factors. Helsinki: The Social Insurance Institution of Finland; 2012. p. 49.

17. Finnish Centre for Pensions. Earnings-related pension recipients in Finland 2015. Helsinki: Finnish Centre for Pensions; 2015. p. 45.

18. Bergh H, Marklund B. Characteristics of frequent attenders in different age and sex groups in primary health care. Scand J Prim Health Care. 2003:21:171-7.

19. Karlsson $H$, Lehtinen $V$, Joukamaa M. Psychiatric morbidity among frequent attender patients in primary care. Gen Hosp Psychiatry. 1995;17:19-25.

20. Lie A, Baranski B, Husman K, Westerholm P, editors. Good Practice in Occupational Health Services: A Contribution to Workplace Health. Copenhagen: WHO Regional Office for Europe; 2002. p. 27-35.

21. Lappalainen L, Liira J, Lamminpää A, Rokkanen T. Work disability negotiations: supervisors' view of work disability and collaboration with occupational health services. Disabil Rehabil. 2018. https://doi.org/10.1080/ 09638288.2018.1455112.

22. Luciano JV, Fernández A, Pinto-Meza A, Luján L, Bellón JA, García-Campayo $J$, et al. Frequent attendance in primary care: comparison and implications of different definitions. Br J Gen Pract. 2010;60:e49-55.

23. Norton J, David M, De Roquefeuil G, Boulenger JP, Car J, Ritchie K, et al. Frequent attendance in family practice and common mental disorders in an open access health care system. J Psychosom Res. 2012;72:413-8.

24. Foster A, Jordan $K$, Croft P. Is frequent attendance in primary care diseasespecific? Fam Pract. 2006;23:444-52.

25. Jyväsjärvi S, Keinänen-Kiukaanniemi S, Väisänen E, Larivaara P, Kivelä SL. Frequent attenders in a Finnish health Centre: morbidity and reasons for encounter. Scand J Prim Health Care. 1998;16:141-8.

26. Ikonen $A$, Räsänen $K$, Manninen $P$, Rautio $M$, Husman $P$, Ojajärvi $A$, et al. Use of health services by Finnish employees in regard to health-related factors: the population-based health 2000 study. Int Arch Occup Environ Health. 2013;86:451-62.

27. Ikonen A, Räsänen K, Manninen P, Rautio M, Husman P, Ojajärvi A, et al. Work-related primary Care in Occupational Health Physician's practice. J Occup Rehabil. 2012;22:88-96.

28. Martimo K-P, Mäkitalo J. The status of occupational health services in Finland and the role of the Finnish Institute of Occupational Health in the development of Occupational health services. Helsinki: Finnish Institute of Occupational Health; 2014. p. 3-6.

29. Haroun D, Smits F, van Etten-Jamaludin F, Schene A, van Weert H, ter Riet G. The effects of interventions on quality of life, morbidity and consultation frequency in frequent attenders in primary care: a systematic review. Eur J Gen Pract. 2016;22:71-82.

30. Van Oostrom S, Driessen $M$, de Vet $H$, Franche $R$, Schonstein $E$, Loisel $P$, et al. Workplace interventions for preventing work disability (review). Cochrane Database Syst Rev. 2009;(Issue 2):1-67. Art. No.: CD006955. https://doi.org/ 10.1002/14651858.CD006955.pub2.

31. Smits FTM, Wittkampf KA, Schene AH, Bindels PJE, Van Weert HCPM. Interventions on frequent attenders in primary care. A systematic literature review Scand J Prim Health Care. 2008;26:111-6.

32. Suija K, Kalda R, Maaroos H-I. Patients with depressive disorder, their co-morbidity, visiting rate and disability in relation to self-evaluation of physical and mental health: a cross-sectional study in family practice. BMC Fam Pract. 2009;10. https:// doi.org/10.1186/1471-2296-10-38.

33. Kimanen A, Manninen $P$, Räsänen $K$, Rautio M, Husman P, Husman K. Factors associated with visits to occupational health physicians in Finland. Occup Med. 2010;60:29-35.

34. Loengaard K, Bjorner JB, Fink PK, Burr H, Rugulies R. Medically unexplained symptoms and the risk of loss of labor market participation - a prospective study in the Danish population. BMC Public Health. 2015;15. https://doi.org/ 10.1186/s12889-015-2177-4.

35. Bergh $H$, Baigi A, Marklund B. Consultations for injuries by frequent attenders are found to be medically appropriate from general practitioners' perspective. Scand J Public Health. 2005;33:228-32.

36. Enterprises, 2016. Statistics Finland, Structural business and financial statement statistics. https://www.tilastokeskus.fi/tup/suoluk/suoluk_yritykset. html. Accessed 21 May 2018

Ready to submit your research? Choose BMC and benefit from:

- fast, convenient online submission

- thorough peer review by experienced researchers in your field

- rapid publication on acceptance

- support for research data, including large and complex data types

- gold Open Access which fosters wider collaboration and increased citations

- maximum visibility for your research: over $100 \mathrm{M}$ website views per year

At $\mathrm{BMC}$, research is always in progress.

Learn more biomedcentral.com/submissions 